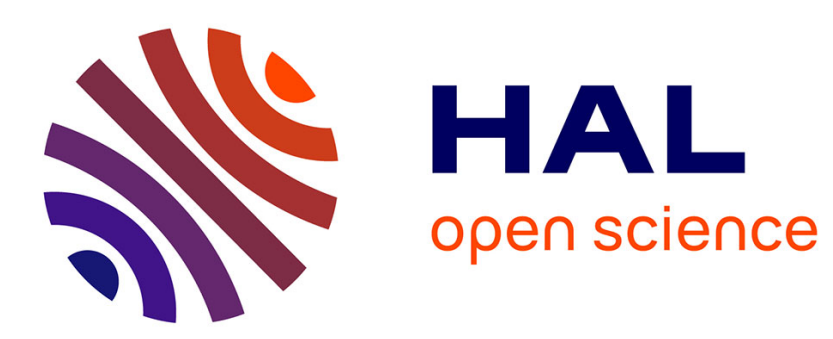

\title{
Structure and properties of TM processed HSLA steels
}

A. Kneissl, P. Baldinger

\section{To cite this version:}

A. Kneissl, P. Baldinger. Structure and properties of TM processed HSLA steels. Journal de Physique IV Proceedings, 1993, 03 (C7), pp.C7-77-C7-82. 10.1051/jp4:1993708 . jpa-00251714

\section{HAL Id: jpa-00251714 https://hal.science/jpa-00251714}

Submitted on 1 Jan 1993

HAL is a multi-disciplinary open access archive for the deposit and dissemination of scientific research documents, whether they are published or not. The documents may come from teaching and research institutions in France or abroad, or from public or private research centers.
L'archive ouverte pluridisciplinaire HAL, est destinée au dépôt et à la diffusion de documents scientifiques de niveau recherche, publiés ou non, émanant des établissements d'enseignement et de recherche français ou étrangers, des laboratoires publics ou privés. 


\title{
Structure and properties of TM processed HSLA steels
}

\author{
A.C. KNEISSL and P. BALDINGER \\ Institute of Physical Metallurgy and Materials Testing, Montan-University of Leoben, Austria
}

\begin{abstract}
This paper deals with the influence of steel composition (with respect to the microalloying elements) and thermomechanical treatment on structure and mechanical behaviour of HSLA (High Strength Low Alloy) steels. Four different microalloyed steels have been TM rolled under variing conditions. The austenite structure prior to transformation could be revealed by means of a special etching technique. The precipitation behaviour has been studied by TEM, STEM and APFIM investigations. The results of mechanical testing can be explained in terms of structure (both austenite and transformed material), steel composition and TM treatment. It could be shown how precipitates in different steels influence the recrystallization behaviour of the austenite and how the austenite structure is related to the transformed structure. For example, fine strain-induced $\mathrm{Nb}$ carbonitrides prevent or reduce recristallization. Addition of Ti leads to relatively coarse complex carbonitrides. As a consequence, the content of solute $\mathrm{Nb}$ decreased and only few $\mathrm{Nb}$ carbonitrides precipitate during deformation. Hence the Ti-bearing steel shows a stronger tendency for recrystallization and the mechanical properties (especially the low-temperature ductility) deteriorate.
\end{abstract}

\section{Introduction}

HSLA steels are of increasing importance for many applications such as linepipe steels, shipbuilding and offshore steels, pressure vessels and automotive structures. By adding of so-called microalloying elements (usually small contents of niobium, vanadium and titanium) to mild steel composition in combination with thermomechanical processing (TMP), remarkable improvements of the mechanical properties could be achieved during the last 25 years. These steels receive their favourable combination of high yield strength and low-temperature toughness mainly by a fine-grained microstructure inherited from an austenite which has been rolled well below the recrystallization-stop-temperature and thereby becomes elongated and flat and exhibits a large surface area per unit volume and many additional sites for ferrite nucleation at deformation bands within the grains. The present paper deals with the influence of steel composition and thermomechanical treatment on the structure and the mechanical properties of HSLA steels.

\section{Experimental}

The compositions of the steels used in this investigations are given in Table I. Steel $A$ represents the basic composition with about $0.1 \% \mathrm{C}, 0.3 \% \mathrm{Si}, 1.4 \% \mathrm{Mn}, 120 \mathrm{ppm} \mathrm{N}$ and $0.15 \mathrm{~V}$. In addition, steel $\mathrm{B}$ contains $0.05 \% \mathrm{Nb}$, steel $\mathrm{C} 0.05 \% \mathrm{Ti}$ and steel $\mathrm{D}$ contains $\mathrm{Nb}$ and $\mathrm{Ti}$ as well.

The thermomechanical treatment started for all samples with soaking at $1150^{\circ} \mathrm{C}$ for half an hour. Up to this temperature, no extensive grain coarsening was observed in previous experiments [1]. The reduction of thickness was $40 \%$ during roughing (4 passes) and $60 \%$ during finishing (7 passes). There have been variations of the TM parameters with respect to the final temperature of roughing (either above or below the recrystallization-stop-temperature), the final rolling temperature (above or below $A_{r 3}$ ) and the cooling rate, as can been seen in Table II. 


\begin{tabular}{|c|c|c|c|c|c|c|c|c|c|c|c|c|c|c|c|}
\hline & c & Si & $M n$ & $P$ & $s$ & A1 & $\mathrm{Cr}$ & $\mathrm{Ni}$ & Mo & $\mathrm{Cu}$ & $y$ & 110 & TI. & $O(p p m)$ & $N(\mathrm{ppm})$ \\
\hline A & 0.096 & 0.30 & 1.47 & 0.008 & 0.003 & 0.04 & 0.043 & 0.031 & 0.003 & 0.029 & 0.16 & & 3 & 78 & 120 \\
\hline B & 0.095 & 0.30 & 1.46 & 0.009 & 0.003 & 0.046 & 0.044 & 0.032 & 0.004 & 0.03 & 0.15 & 0.03 & $\sqrt{3.0}$ & n.b. & 128 \\
\hline c & 0.097 & 0.29 & 1.44 & 0.009 & 0.002 & 0.041 & 0.033 & 0.026 & 0.004 & 0.028 & 0,5 & 3. & 0048 & 40 & 122 \\
\hline D & 0,099 & 0.29 & 1.44 & 0.009 & 0.002 & 0.044 & 0.033 & 0.026 & 0.004 & 0.03 & 0.15 & 00047 & 0.047 & n.b. & 124 \\
\hline
\end{tabular}

Table I. Chemical compositions of steels investigated, wt.-\%.

\begin{tabular}{|c|c|c|c|c|c|c|}
\hline & $\begin{array}{c}\text { soaking } \\
\text { temperature }\end{array}$ & $\begin{array}{c}\text { final temperature } \\
\text { of roughing }\end{array}$ & $\begin{array}{c}\text { A } \mathbf{3} \\
\text { calculated }\end{array}$ & $\begin{array}{c}\text { final rolling } \\
\text { temperature }\end{array}$ & $\begin{array}{c}\text { air cooling } \\
{[\mathrm{K} / \mathrm{s}]}\end{array}$ & $\begin{array}{c}\text { oil } \\
{[\mathrm{K} / \mathrm{s}]}\end{array}$ \\
\hline A & 1150 & $900 / 950$ & $760-772$ & $750 / 800$ & 1 & 25 \\
\hline B & 1150 & 950,1000 & $760-773$ & $750 / 800$ & 1 & 25 \\
\hline C & 1150 & 900,950 & $762-775$ & 750,800 & 1 & 25 \\
\hline D & 1150 & 950,1000 & $761-774$ & 750,800 & 1 & 25 \\
\hline
\end{tabular}

Table II. Variation of the TM rolling parameters.

The $A_{r 3}$-temperatures of the different steels have been calculated according to $[2,3]$. By the treatment described above one gets eight different TM conditions per alloy. A very essential point of this investigation was the characterization of the austenite structure prior to transformation with respect to the grain-size distribution. A modified austenite grain etching technique described in [4] has been used successfully for fulfilling this task. It has been shown that different alloys and different thermomechanical treatments require different ratios of picric and hydrochloric acid which can be controlled by measuring carefully the $\mathrm{pH}$-value. The transformation structure has been characterized by conventional etching techniques and quantitative metallography.

In addition, it was necessary to investigate the precipitation behaviour of the different steeis during thermomechanical treatment in order to explain structural changes caused by recrystallization or its prevention. Therefore carbon extraction replicas have been prepared for investigation with STEM and EDS following the usual techniques, for example see reference [5].

In order to detect and analyze the smallest particle population which can hardly be seen with the TEM, a field ion microscope with an atom-probe mass spectrometer (APFIM) has been used. The procedure of sample preparation for the APFIM has been reported in reference [6].

Finally tensile tests and charpy $V$ notch tests have been performed to measure and compare the mechanical properties of the specimens investigated.

\section{Results and Discussion}

Since there are 32 different samples a lot of data has been acquired concerning the characterization of structure and the mechanical properties. In the following, some of the essential results will be presented and discussed.

First a comparison is given [Fig. 1] of the strength properties of the four different steels after the same kind of thermomechanical rolling has been applied (roughing above the recrystallizationstop-temperature, finishing within the $\gamma$-region and oil-quenching). 


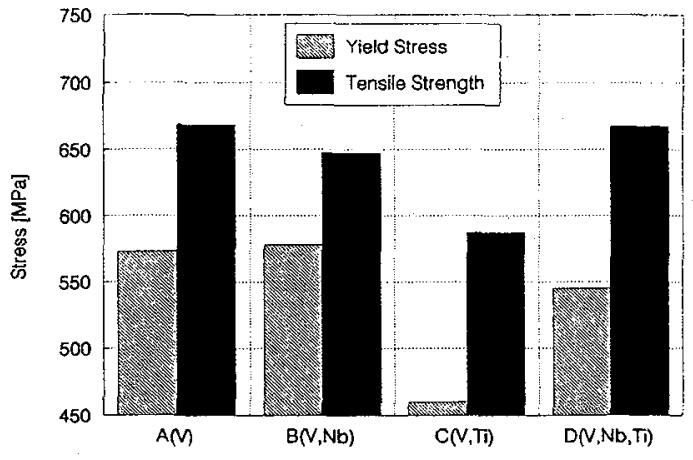

Fig. 1: Yield and tensile strength of the four steels.

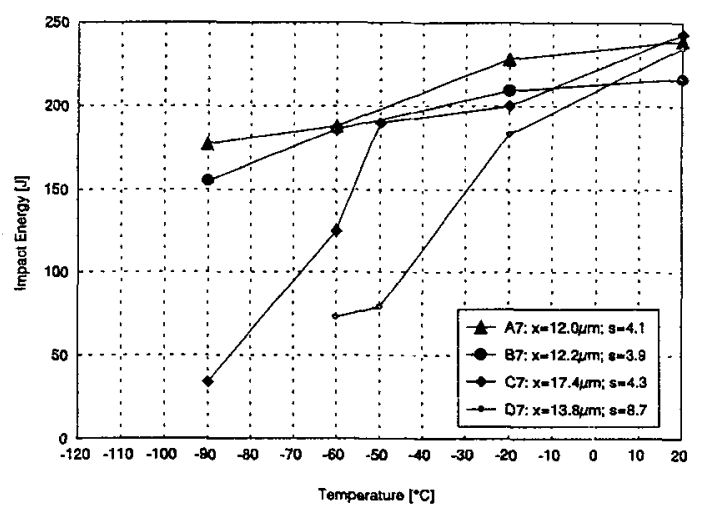

Fig. 3: Results of charpy $V$ notch tests.

The steels $A, B$ and $D$ have similar strength properties but $C$ shows much lower values. This different behaviour can be explained by structural differences, as can be seen in Fig. 2 .

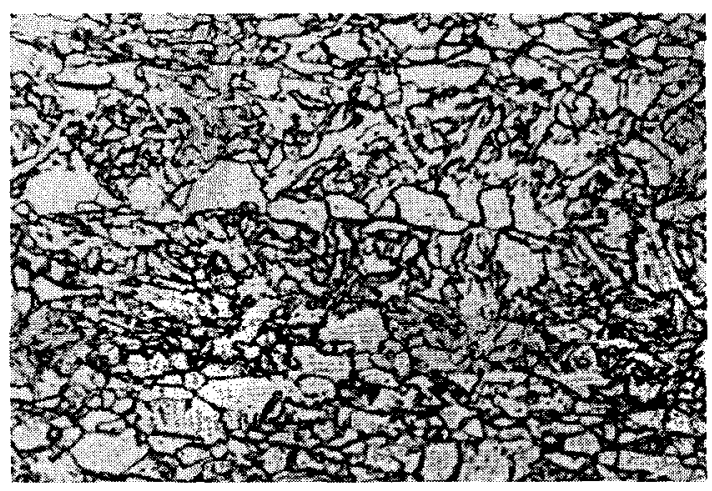

A

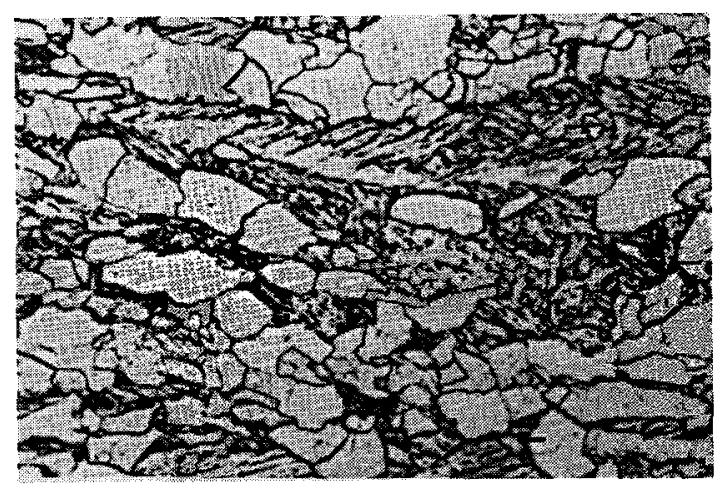

C

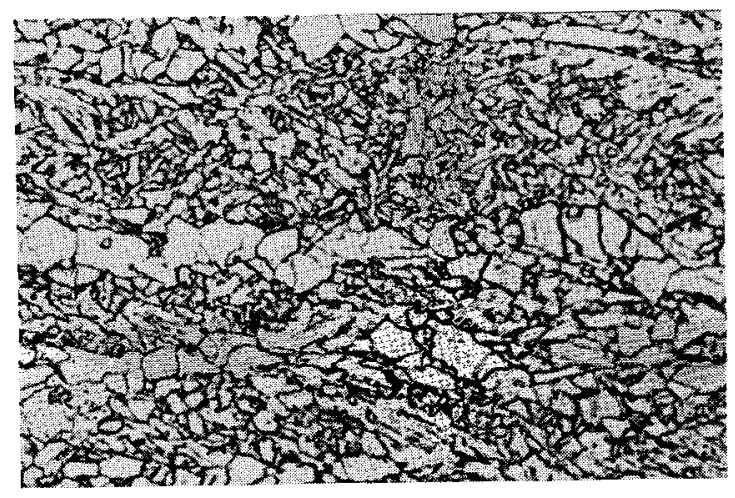

B

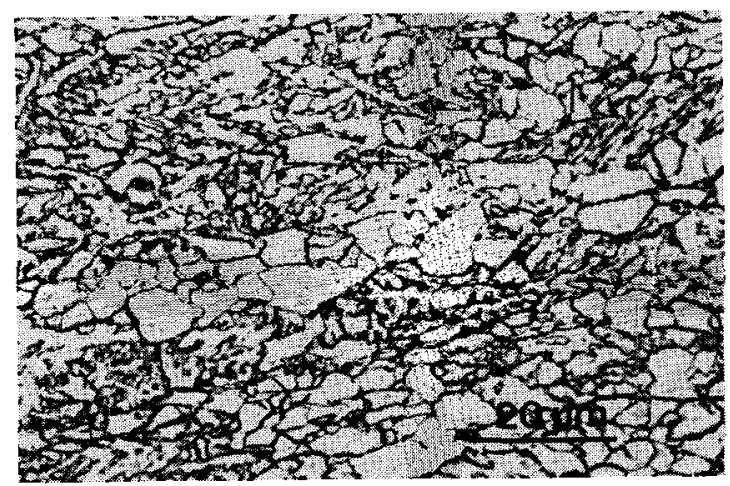

D

Fig. 2: Transformed structure of the four steels.

The transformed structure consists of bainite and ferrite. Whereas A, B and D exhibit about $40 \%$ ferrite (which has been established by quantitative metallography), steel C contains over $50 \%$ ferrite. Moreover, the ferrite grains are much coarser, inherited from a coarser austenite structure. The reasons for this coarser structure will be given later on. Now, the same samples will be compared with respect to their low-temperature toughness (Fig. 3). 
The steels $A(V)$ and $B(V, N b)$ show high impact energy values down to $-90^{\circ} \mathrm{C}$ which is caused by a small and homogeneous austenite grain. The value $x$ denotes the average thickness of the elongated austenite grains. Steel $C(V, T i)$ has a coarser austenite structure and steel $D(V, N b$, Ti) exhibits a relatively fine mean austenite grain but with a high standard deviation $\mathbf{s}$.

Obviously there are differences in the recrystallization behaviour, therefore it was necessary to investigate the precipitation processes and their influence on recrystallization and grain growth. The question is, whether particles would be able to prevent grain boundary migration and recrystallization or not. Critical particle sizes can be assessed by balancing the driving and the retarding forces. The driving force for primary recrystallization is given by the difference between the dislocation densities in the deformed and recrystallized state. The energy per unit length of a dislocation is proportional to $G^{*} b^{2}$, therefore

$$
p_{1}=\alpha * G * b^{2 *} \Delta \rho
$$

with $\alpha$ (geometry factor) about $1, \mathrm{G}=8.1 * 10^{4} \mathrm{MPa}, \Delta \rho$ about $10^{15} / \mathrm{m}^{2}$ and burgers vector $\mathrm{b}=3^{*} 10^{-10}$ $\mathrm{m}$. Inserting these values in eg. 1 leads to $p_{1}=7^{*} 10^{6} \mathrm{~J} / \mathrm{m}^{3}$ as driving force for the primary recrystallization.

Deriving the driving force for normal grain growth $p_{2}$ under assumption of cubic grains leads to

$$
p_{2}=3 * \gamma / D
$$

For an austenite grain diameter $D$ of $30 \mu \mathrm{m}$ and a specific grain boundary energy of $1 \mathrm{~J} / \mathrm{m}^{2}$ one gets a $p_{2}$-value of $10^{5} \mathrm{~J} / \mathrm{m}^{3}$.

On the other hand particles can lead to pinning of the grain boundaries since they reduce the total grain boundary area. The retarding force $p_{3}$ is given by

$$
p_{3}=Z^{*} \pi^{*} \gamma^{*} d
$$

Since $Z$ (number of particles) equals $4 f / d^{2} \pi$, f being the volume fraction and $d$ the diameter of the particles, we get

$$
p_{3}=4^{*} f * \gamma / d
$$

Inserting $f=1 \%$ which is an upper limit in HSLA steels and comparing $p_{3}$ and $p_{1}$ results in a critical particle diameter $d$ of about $5 \mathrm{~nm}$, below which the recrystallization will be prevented. This value is surprisingly low and it means that the precipitation must take place during or immediately after the deformation (strain-induced precipitation) since otherwise the particles get too coarse.An energy balance between $p_{2}$ and $p_{3}$ leads to a particle diameter of $300 \mathrm{~nm}$ which still can prevent normal grain growth.

Independent of the holding time and deformation temperature a large number of polyhedral particles were detected on the replicas of the $\mathrm{V}$ - Nb-Ti steel $\mathrm{D}$ with sizes ranging from about $50 \mathrm{~nm}$ to $200 \mathrm{~nm}$. Many of these are arranged in rows (Fig. 4) indicating thereby the position of former austenite grain boundaries.

Using an EDS analyzing system these precipitates turned out to be TiNb carbonitrides, the composition of which changes with size making the larger ones Ti-rich and the smaller ones $\mathrm{Nb}$-rich. In addition to this family of precipitates some V-rich carbonitrides could be found in samples deformed at low temperatures after long holding times. These are also polyhedral and about $50-100 \mathrm{~nm}$ in size. Furthermore there are some relatively large Ti nitrides (about several $\mu \mathrm{m})$ which can be seen easily on optical micrographs of Ti-bearing steels.

The examination of $\mathrm{V}-\mathrm{Nb}$ steel replicas (steel $\mathrm{B}$ ) treated with or without deformation gave the following results: After short holding times some Al-rich particles (probably Al nitrides) were found. At longer holding times a few $V$-rich precipitates occured and - even less frequent - some Nb-rich particles (10-20 nm of size). However, studying these samples with the field-ion microscope gave proof that very tiny precipitates (below $5 \mathrm{~nm}$, Fig. 5) form in the deformed material after short times. Using the atom-probe these particles can be characterized as $\mathrm{Nb}$ carbides with very small contents of $\mathrm{V}, \mathrm{Ti}$ and $\mathrm{N}$. 


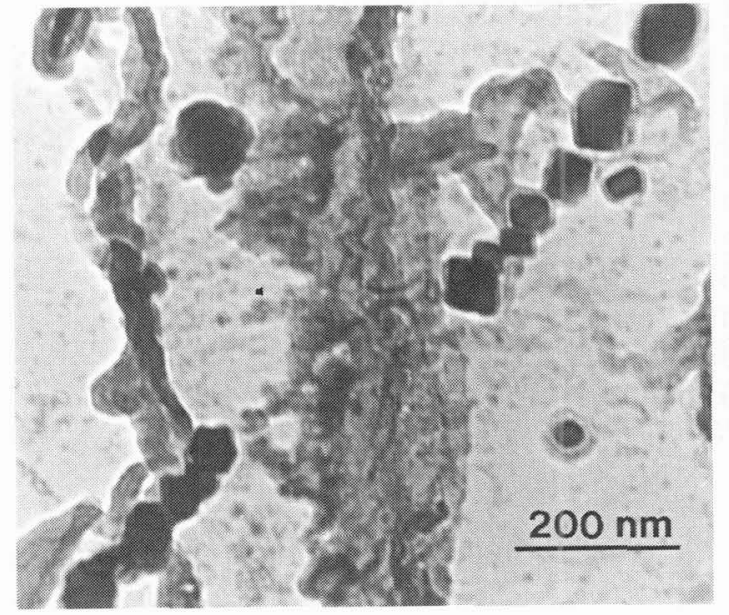

Fig. 4: Particles in steel D, STEM.

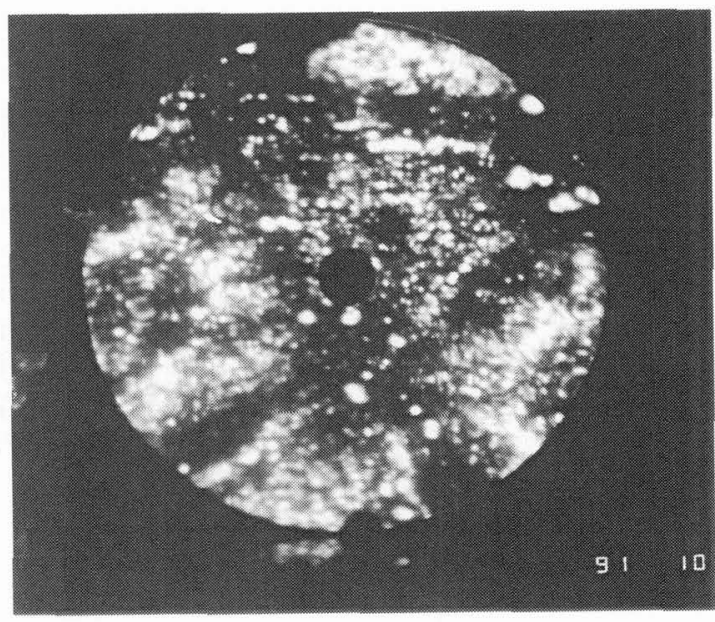

Fig. 5: Nb carbides in steel B, FIM.

These results are summarized in Fig. 6a and 6b showing PTT (precipitation-time-temperature) diagrams of both steels. $P_{s}$ means start of precipitation without deformation, $P_{s}{ }^{D}$ stands for start of precipitation in deformed samples. In the $\mathrm{V}-\mathrm{Nb}$-Ti steel the ultra-fine $\mathrm{Nb}$ precipitates appear later and are less numerous compared to the Ti-free steel.

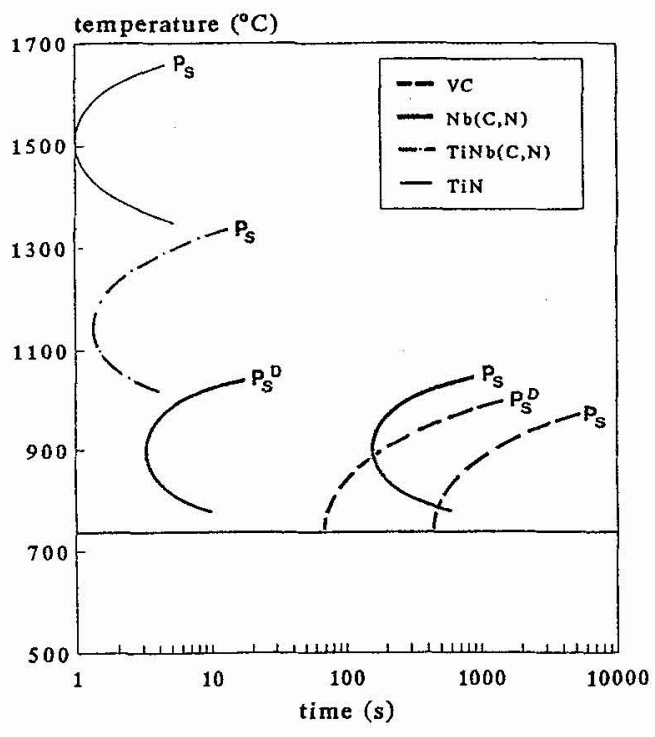

Fig. 6a: PTT diagram of steel D.

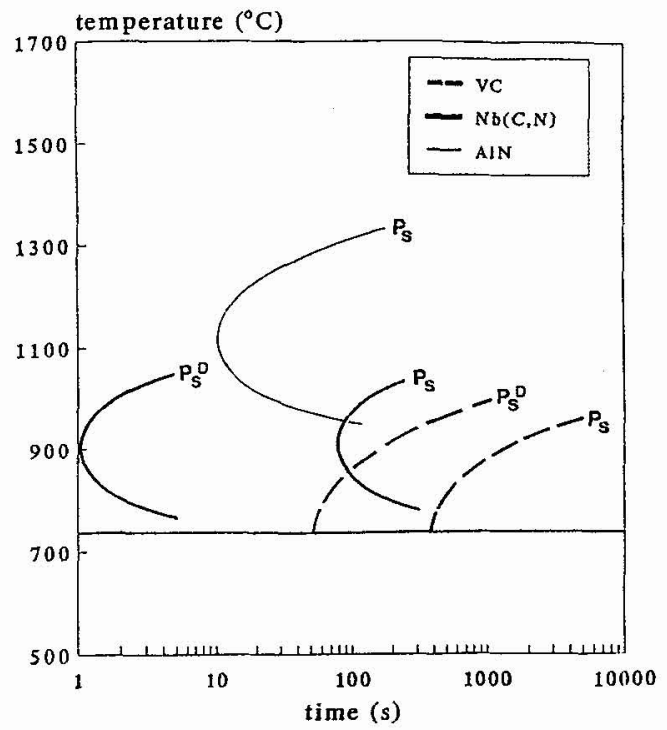

Fig. 6b: PTT diagram of steel B.

The main result of this comparison is that the addition of Ti to the $\mathrm{V}$-Nb bearing steel leads to the formation of relatively large complex TiNb carbonitrides which cannot prevent recrystallization, but as a consequence, the supersaturation of $\mathrm{Nb}$ in the austenite at deformation temperature is small and so a much smaller number of strain-induced precipitates is formed. The different recrystallization behaviour of steel $D$ and $B$ is shown in Fig. 7 indicating a stronger tendency to recrystallize for the $\mathrm{V}$-Nb-Ti steel which leads to the inhomogeneous austenite grain structure observed in this steel. Thus, the deterioration of the low-temperature ductility can be explained (compare Fig. 3 ). 


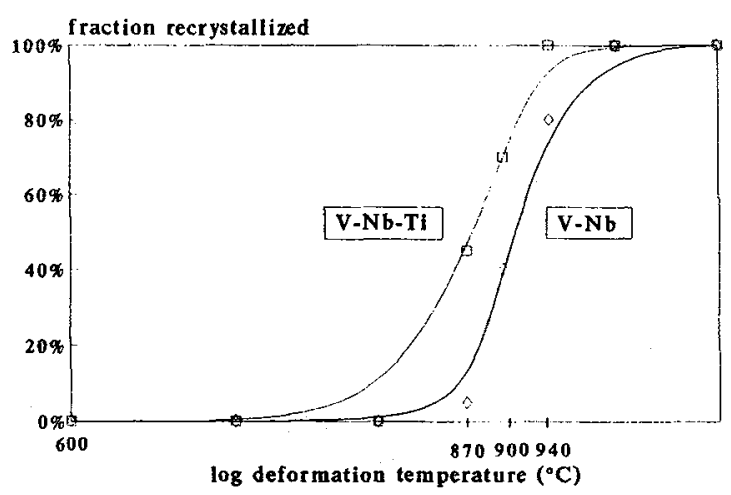

Fig. 7: Degree of recrystallization versus temperature at a constant holding time of $10 \mathrm{sec}$

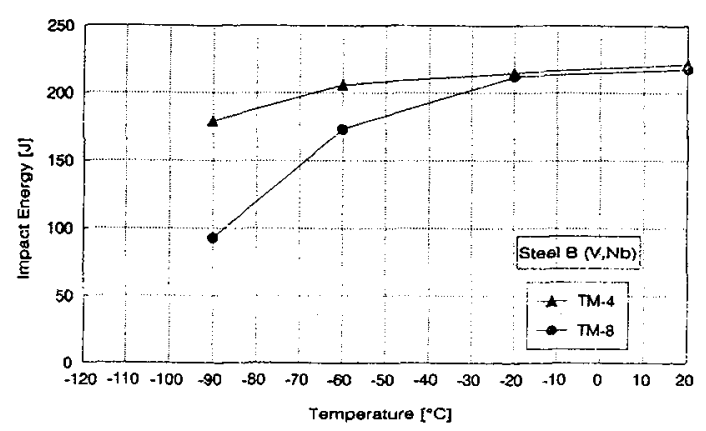

Fig. 8: Charpy V notch tests of B4 and B8.

The $V$-bearing steel $A$ shows many fine strain-induced precipitates ( $V$ nitrides and carbonitrides). By Ti additions (steel C) coarse TiN are formed, therefore the nitrogen content decreases and very few strain-induced precipitates can form since the thermal stability of $V$ carbides is much lower than that of $V$ nitrides, which explains the coarse austenite and ferrite structure of steel $C$.

All steels usually show their best combination of strength and ductility after finishing above $A_{r}$ and oil-quenching (TM treatments 4 and 8 which differ with respect to the final roughing temperature, TM-8 above and TM-4 below the recrystallization-stop-temperature). The latter treatment resulted in a very fine-grained bainitic-ferritic structure while B8 exhibits much coarser plate-like bainite grains. During the final roughing pass no recrystallization takes place in B4 therefore this strain adds to the finishing deformation which gives additional sites for the ferrite nucleation at deformation bands within the grains and thus explains the finer structure and the better ductility (Fig. 8).

\section{Summary}

Four microalloyed steels experienced TM rolling treatments with variing conditions. The mechanical properties have been related to the microstructures, and the formation of these structures has been explained by the precipitation and recrystallization behaviour of the austenite. The best overall properties (strength and I.ow-temperature ductility) are gained by specific treatments of steel $A(V)$ and $B(V, N b)$. Steel $D(V, N b, T i)$ generally has good strength properties but lower impact energy values at very low temperatures compared to $A$ and $B$, while steel $C(V, T i)$ is low in strength and ductility as a consequence of a relatively coarse austenite structure.

\section{Acknowledgement}

The authors gratefully acknowledge the support of this work by the Austrian Science Foundation (Fonds zur Förderung der wissenschaftlichen Forschung, FWF).

\section{References}

[1] M. Kirchgassner, et al.; Sonderbände der Praktischen Metallographie 23, Carl Hanser Verlag, München-Wien (1992) 131

[2] C. Ouchi, T. Sampei and I. Kozasu; Trans. ISIJ 22 (1982) 214

[3] C. Chiga et al; Conf. Proc. on HSLA Steels: Technology and Application, ASM, Metals Park, Ohio (1984) 643

[4] P. Baldinger, G. Posch, A.C. Kneissl; Sonderbände der Praktischen Metallographie 24, Carl Hanser Verlag, München-Wien (1993)

[5] A.C. Kneissl, C.I. Garcia, A.J. DeArdo; HSLA Steels: Processing, Properties and Applications, The Minerals, Metals and Materials Society, Warrendale (1992) 99

[6] A.C. Kneissl, S.S. Brenner; Practical Metallography 27 (1990) 159 